\title{
Review of behavioral finance as an emerging field of investment decision making
}

\author{
Anjum Raza
}

\section{Introduction}

Financial decision making is a process involving multiple variables. Some of these include economic activities taking place in the country as well as the world, the political, information and institutional constraints and the accessibility of the investors to financial instruments. Contemporary research in the field of financial investments however for example the one conducted by Hoseini (2003) shows that important factors influencing financial investments include the process of decision making of the investors and the perceptions of the investors in regards to the economic, company specific and instrument specific variables. Given the pace of communication and information, financial markets have been opened up to not only institutional but also individual investors.Thismeans that the number of players and the impact of investor perceptions have increased significantly thus increasing the importance of research that looks at the cognitions, perceptions, attitudes and then finally the resulting investment behaviors of individuals. This premise has led to the creation of the field of behavioral finance which currently is largely in its phase of development. A number of institutional and individual researchers are working on this field to avail the potential that this understanding has to offer. What is important however is for some research to simultaneously sum up the important developments in this field so that corporate investors, financial managers as well as the future researchers can have an overview of what has been going on in this field up till now.

This paper is aiming to review the important developments in the field of behavioral financial and to present how behavior finance is the emerging field in the area of investment decision making. In this the paper will be highlighting the origin and the factors that have contributed to making behavioral finance termed as an emerging field of financial decision making given the competitive school of thought and researches that already exist (Jegadeesh, 1995).

Specifically this research is aiming to highlight:

i) What behavioral finance offers for investment decision making

ii) How and why is behavioral finance an area of controversy in financial decision making

iii) What is the projected future for the field of behavioral finance keeping in view the value of contributions that the research is making

iv) How can researchers and financial theorists work tofurther the value of their contributions in the field of behavioral finance?

In order to achieve the aims of this research, an in depth and critical review of the work done in the field of behavioral finance be conducted. It is expected that in the research pool that is available especially by the Pakistani researchers, this paper will be a significant mark.

\section{Development of Behavioral Finance Theory}

\section{Literature Review}

According to Shiller (2003), academic finance has evolved significantly. The process of evolution can be considered to have started from the efficient market theory and up till now the behavioral finance theory. Given the rise in the dominance of rational expectations theory in the 1970s, the efficient market theory also reached the height of its dominance. This was because of the close alignment that occurred between the theoretical trends of that time and the idea that the best information available is incorporated by the movements in the asset and stock process. One of the most striking examples of work in this field is the paper "An Intertemporal Capital Asset Pricing Model" by Robert Merton (1973) that presented movement from generalized asset pricing model to an inter temporal equilibrium model.

Helen and Simon (2000) say that behavioral finance started emerging as a new vision in the publications of finance during the 1990s however the actual origins of this field can be dated back up to 150 years. For example the publication by MacKay in 1841, "The Delusions and the madness of crowds" talked about how various elements have the tendency to create panic and reactions amongst groups and individuals. This work is often used to explain many of the possibilities and individual behavior in financial markets and individual behaviors. Another great piece of literature that made striking contributions to the field of behavioral finance was by Selden (1912) through the book called "Psychology of the stock market" in which the author directly applied the concepts, theories and arguments of psychology to explain the stock market movements. In 
this the emotional as well as the psychological forces that impact the cognitions as well as the behaviors of the investors and brokers in the financial markets have been focused upon.

Probably the most important proposition of behavioral finance is that it is an amalgamation of a number of different schools and fields previously developed regarding finance. This means that the researchers, theorists, practitioners and scholars working on and applying behavioral finance have the background of various financial disciplines making behavioral finance an umbrella that can be considered an explanation of trading and investment decision making in the field of finance.

\section{Controversy Surrounding Behavioral Finance}

Behavioral finance currently is termed to be a separate field from "Standard finance" which basically refers to the accepted theories that exist currently. The basis of standard finance is the Modern Portfolio Theory and the Efficient Market Hypothesis (Helen and Simon, 2000). As is well known the Modern Portfolio Theory talks uses the three concepts of expected portfolio return, the deviation of the returns from the expected and the correlation of one stock with the others held in a portfolio. The theme of Efficient Market Hypothesis on the other hand states that the asset and stock market prices reflect the information that is available in the market as well as the individual investor regarding the market movements, the economic movements as well as the regarding the fundamentals of the stock.

These widely held and accepted theories are in stark contrast with the propositions of those of behavioral finance according to which the reasons behind the financial decision making of the investors include the emotional aspects impacting the investor, the mental state of the investor while taking the investment decisions and then most importantly the pattern that the other investors in the market are following in regards to the investment decision making.

\section{Research Methodology}

Research methodology relates to the ways and the means to be adopted to meet the objectives of the research. It includes research design, research methods, sampling techniques and methods of data collection. Unit of analysis, which is the entity to be studied under the research, is also defined in research methodology. In the following paragraphs, research methodology adopted for this research has been elaborated. (Saunders, M., 2009)

\section{Research Design}

Research design of this study is the case study method. The cases are the markets and the individual investors. This approach has been used because contextual understanding of the factors that make markets and the individual investors take decisions is required. Such a contextual understanding can allow insights into the dynamics of behavior finance, in line with the aims of this research. Deeper understanding of behavior patterns of the individuals as well as the markets shall also allow the researcher to predict the future of behavior finance as a specialized field.(Saunders, M., 2009) Under the case study approach, qualitative and quantitative techniques of data collection have been used.

\section{Unit of Analysis}

Unit of analysis is individuals and institutional investors. These two units of analysis have been selected because the whole idea of the field of behavior finance revolves around them. Their decision making patterns today or tomorrow shall determine the future of this field, and shall add value to the existing literature on behavior finance. Thus, these units of analysis are consistent with the aims of this research.

\section{Research methods}

Secondary data has been collected under the qualitative research method. Quantitative analysis has been done on questionnaires, which were prepared to gauge the behavior patterns of the individuals and the markets, and to predict the future of the field of behavior finance. (Ghauri, P., 2005)

\section{Time horizon}

Cross-sectional time horizon has been used. The aim of the research is to find out the nitty-gritty of the field of behavior finance, using individuals' behavior and the market's behavior and make predictions about its future. This can be achieved by analyzing secondary and primary data at one time.(Ghauri, P., 2005)

\section{Primary data collection}

Primary data is a data which is collected for the first time. Questionnaire method has been used to collect primary data. Questionnaires are closed-ended and prepared on a Likert Scale. The results of the questionnaires have allowed the researcher to predict the future of this field. This is because the analysis of the behavior patterns and to what extent these impact investment-decision making of the individuals and the markets has been made possible by the results.

Making predictions about the field of behavior finance is a part of the objectives of this research. The questionnaire will also allow the researcher to understand the importance of behavior finance as an emerging 
field, because it will reveal the general attitude of the individual and the institutional investors toward behavior as an investment decision-making force. Hence, it is linked to the topic of this research.

Sample size of the questionnaire is 30 individuals and 20 institutional investors, chosen from the database of Karachi Stock exchange, Lahore Stock exchange and Islamabad Stock exchange.The sampling technique used for this purpose is judgmental sampling. The judgment has been exercised considering that these 30 individuals and 20 institutional investors are representative of the entire population of the individual investors and the institutional investors in Pakistan. The senior finance managers of the institutional investment making organizations like Jahangir Siddiqui \& Co. Ltd. (JSCL), were given the questionnaires. (Ghauri, P., 2005)

The interest in the Pakistani market was because of the recent movements in the stock indices as a result of the political and social movements in the country. This directs towards the fact that investors are affected by the general mass movements in the financial markets and the country overall thus implying that behavioral finance theories have a scope here and will be able to explain the investment decision making and risk factors of the same effectively. Through the questionnaire survey, it was interrogated as to what level to the investors from Karachi Stock Exchange, Lahore Stock Exchange and Islamabad Stock Exchange take the behavioral elements as proposed by behavioral scientists into account. The variables for this purpose have been shortlisted through an in depth literature analysis, a brief review of which is incorporated in this report.

The questionnaire has been prepared by taking into account various dimensions of the human behaviors such as emotions, mental state and the tendency to emulate others. Emotions have been subdivided into happiness, unhappiness, excitement, anxiety, relaxation and mental strain. Mental state has been subdivided into life satisfaction and depression.

These parameters have been incorporated in the questions of the questionnaires, so that the real impact of the behavior of the investors on their investment decision-making can be gauged. Since the objective of this research is to explain the future of behavior finance in the domain of theory and practice, questionnaires have been prepared on a Likert Scale. Likert Scale helps in capturing the extent to which people attach importance to their behavior, for example, it gives the options of Strongly Agree and Strongly Disagree to measure the various degrees of the responses. The measurement of the intensity of the responses regarding the impact of behavior on financial decision-making shall aid the researcher in crafting an appropriate and objective answer to the question of the future of behavior finance as a field.

\title{
Secondary data collection
}

Secondary data has been taken from the documents of stock exchanges, security and exchange commission of Pakistan and various other relevant authorities. The purpose of the analysis of the secondary data is to understand the current controversy surrounding the field of behavior finance, and to get relevant information about the variables of human behavior that are generally linked to financial decision-making. (Ghauri, P., 2005) These variables of human behavior have been added in the questions of the questionnaires. In this way, investors have not found those parameters of behavior unknown, because secondary data has assured the researcher that the investors are influenced by those variables generally. Thus, collection of secondary data has helped in the preparation of the questionnaires, and hence in achieving the objectives of the research.

\section{Quantitative Data analysis}

The results of the questionnaires have been explained with the help of charts. These questionnaires were given to individual investors and the institutional investors. First, the results of the individual investors have been explained, and then those of the institutional investors.

\author{
Analysis of Individual Investors
}




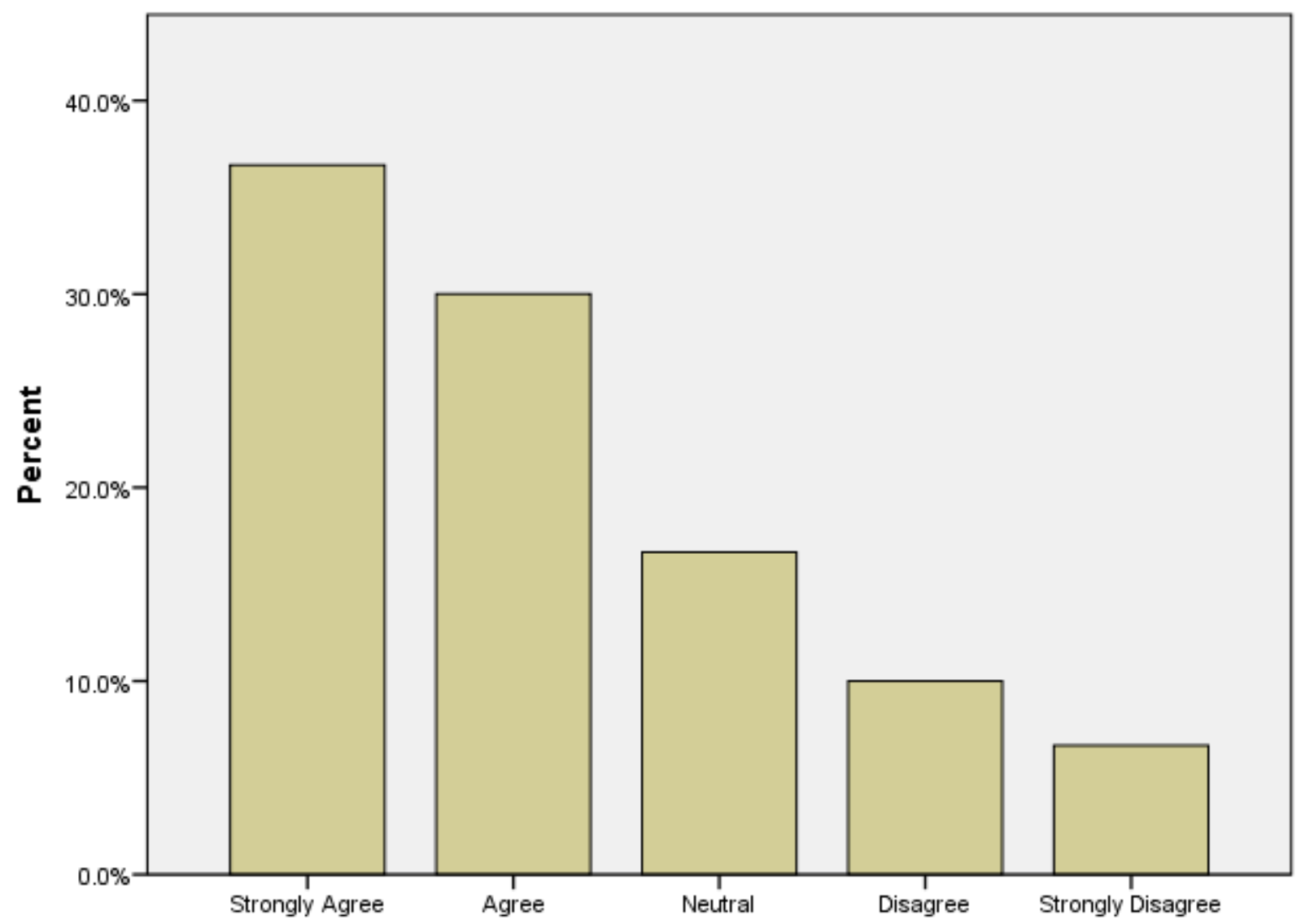

At the time of happiness, a greater number of stocks in the market were purchased than the same type of stocks purchased at the same price at the time of unhappiness?

a. At the time of happiness, a greater number of stocks in the market were purchased than the same type of stocks purchased at the same price at the time of unhappiness?

As the question inquires about the impact of happiness of the individual at a particular time on their investment decision-making, the majority of the respondents have strongly agreed to this statement. An almost $30 \%$ of the respondents have simply agreed to this statement, while $10 \%$ of the respondents have disagreed. On the whole, the results state that behavioral parameters are the strongest reason why individuals buy a particular stock in the market. This is manifested by the fact that the same type of stocks with a same yield and market price have not been bought by the investors when they were unhappy. On the other hand, when they were happy they preferred to buy those stocks. This implies that, more than the price of the stocks and the historical information about the creditor, behavior patterns of the individuals affect their investment decision making. This also shows that behavior finance as a field has a great future, because investors are heavily influenced by their mental states at the time of making decisions. Modern portfolio theory and efficient market hypothesis are not considered by the individual investors, if these results are accounted for. (Helen and Simon, 2000) 


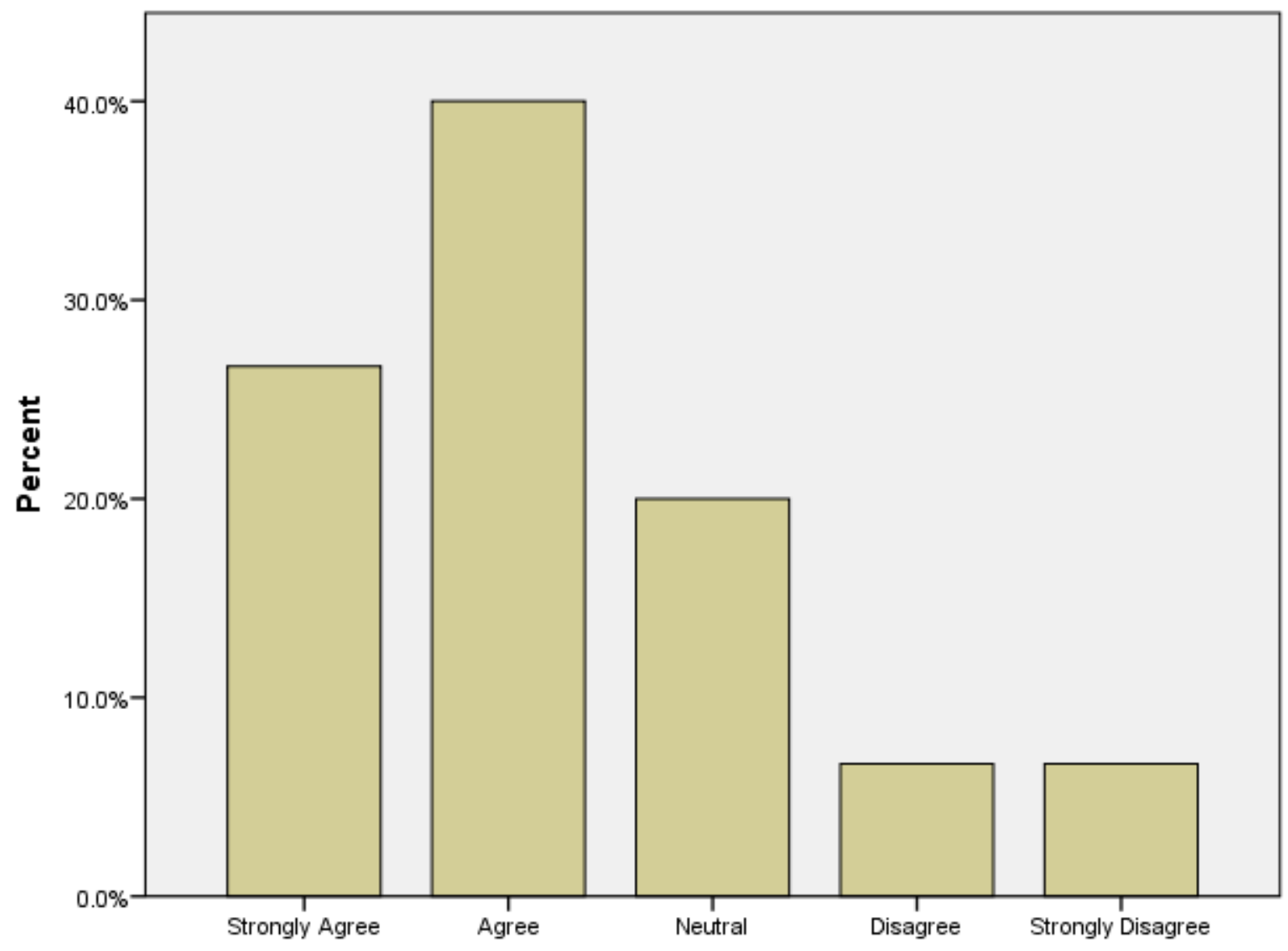

At the time of extreme excitement and enthusiasm, you were more willing to buy risky stocks than at the time of subdued and demoralized attitude?

b. At the time of extreme excitement and enthusiasm, you were more willing to buy risky stocks than at the time of subdued and demoralized attitude?

An overwhelming majority of the respondents have agreed to this question. This stands at $40 \%$. Second to this is the option of strongly agree, which has been ticked by around $25 \%$ of the respondents. The percentage of the respondents who remained neutral is $20 \%$. All in all, the results strongly assert that the excitement level of the investors is a determinant of their risk perceptions at a particular time. This also shows that an investor will be a risk averse at some time, and a risk taker at other occasions. This finding has done away with the modern theoretical notion, which considers the risk averse and the risk taker characteristics of the investors as inalienable and unchangeable part of their personalities. This finding has also shown that behavior finance as a field has a great future, at-least when it comes to analyzing the investment decision-making patterns of the individual investors. 


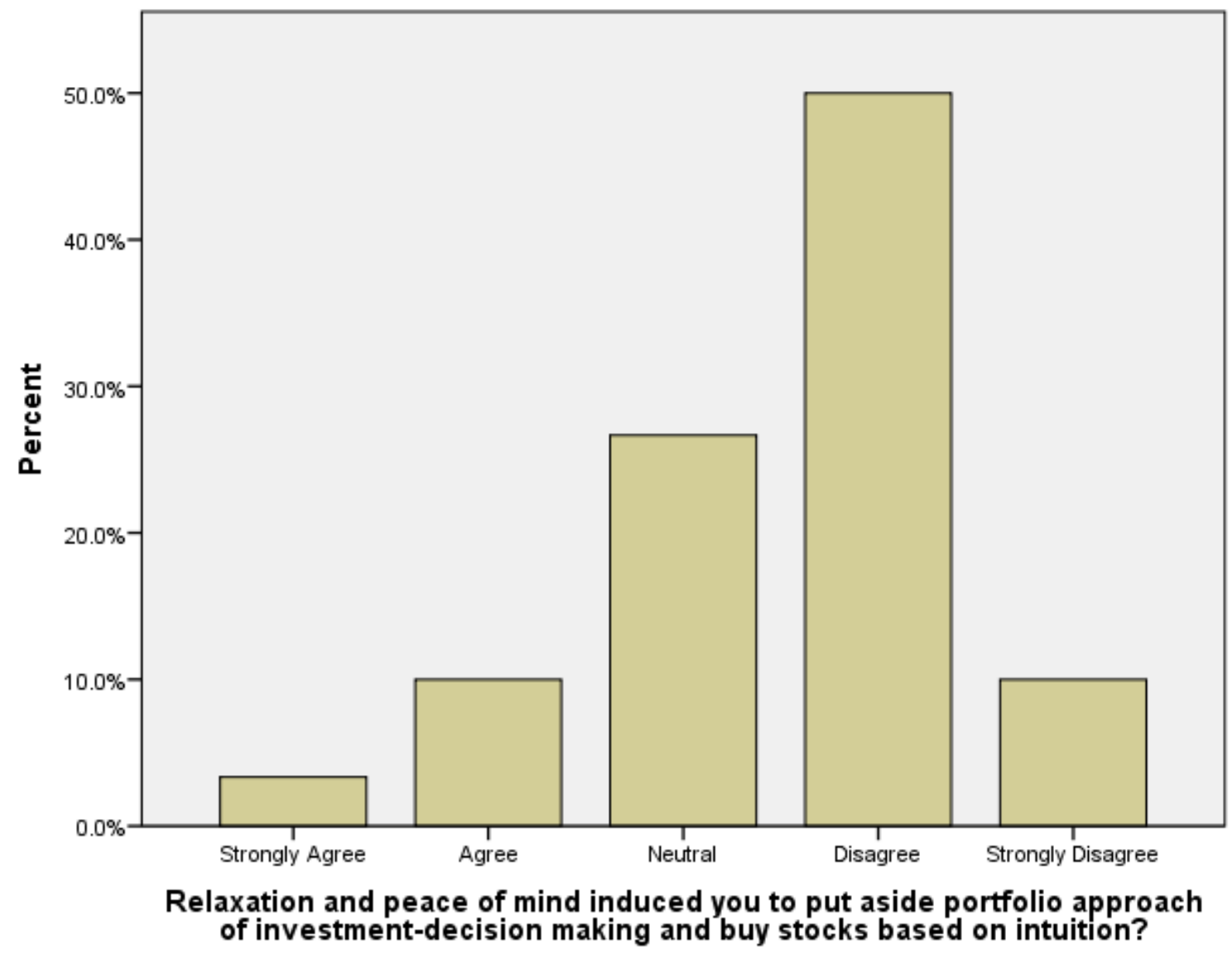

c. Relaxation and peace of mind induced you to put aside portfolio approach of investment-decision making and buy stocks based on intuition?

The results of this question state that an absolute majority of around $50 \%$ of the respondents have rejected this contention, implying that relaxation and peace of mind did not affect their behavior while making investment decisions. An almost $25 \%$ of the respondents have shown neutrality to this statement. These results have affirmed the controversy surrounding behavior finance as a field, for example, in the questions mentioned prior to the above question, it turned out that behavior determined investment decision making pattern of the investors, while in this question this has not been discovered. This suggests that some dimensions of the behavior are more strongly linked to investment decision making than others. (Helen and Simon, 2000) 


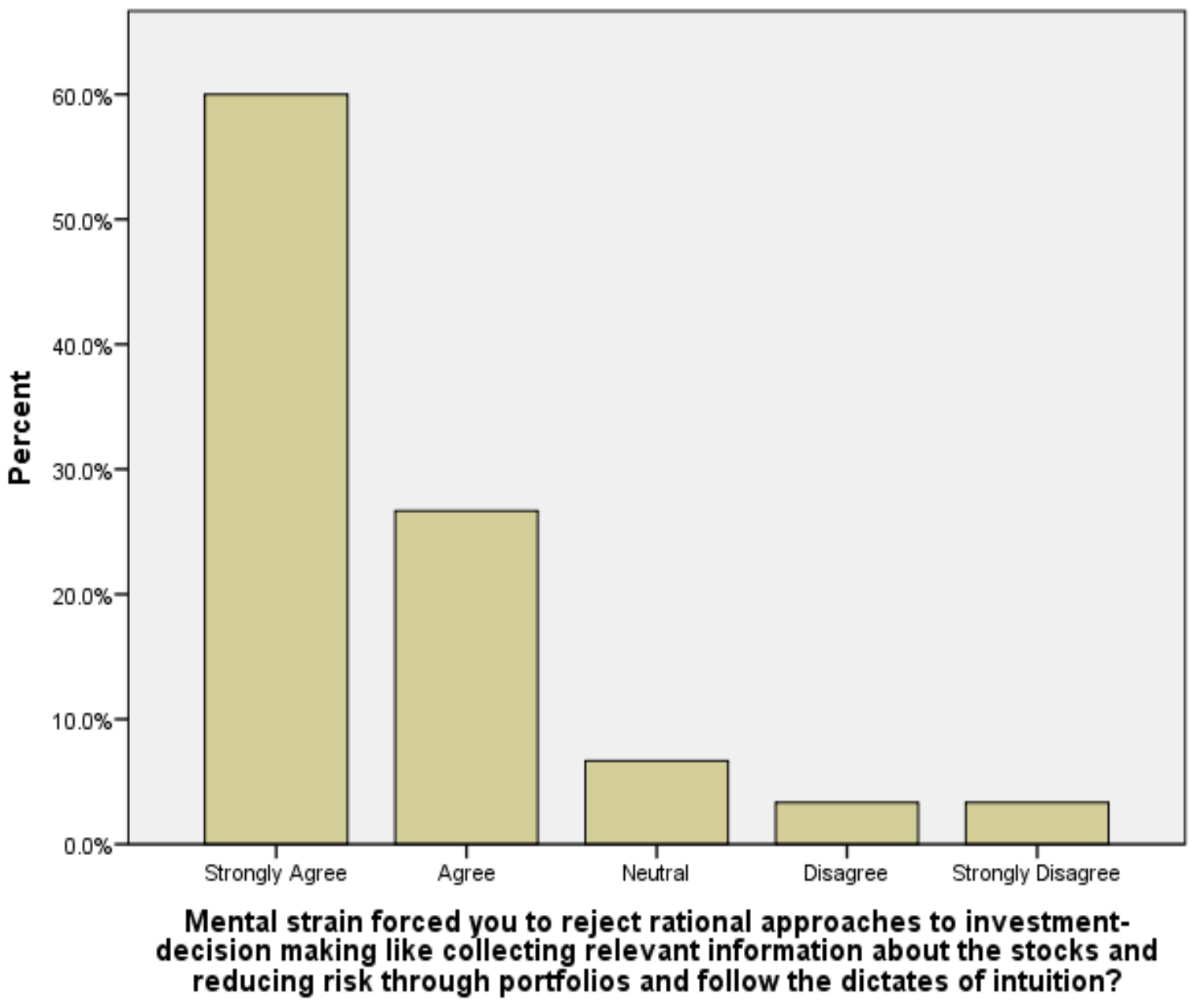

d. Mental strain forced you to reject rational approaches to investment-decision making like collecting relevant information about the stocks and reducing risk through portfolios and follow the dictates of intuition?

The results of this question have confirmed the conclusion, which were drawn from the analysis of the first two questions, stating that behavior impacts investment decision-making of the individuals. As the graph shows, an almost $60 \%$ of the respondents have strongly agreed that mental strains compelled them to make decisions based on their intuition, instead of carrying out portfolio analysis and following rational approaches. The fact that they have strongly agreed shows the extent to which these investors use behavior as a tool to take investment related decisions.

This also shows that doing investment based on intuition pays off, perhaps more than it does in the case of rational decision-making, because otherwise these individual investors would not have strongly agreed to this statement. Irrespective of that, one thing is clear that behavior finance as a field is going to have a special influence on the individuals, in the years to come. Thus, the new individual investors in the market can happily apply their intuition for making investment, because their counterparts have been using it as a tool for decisionmaking as indicated by the above graph. 


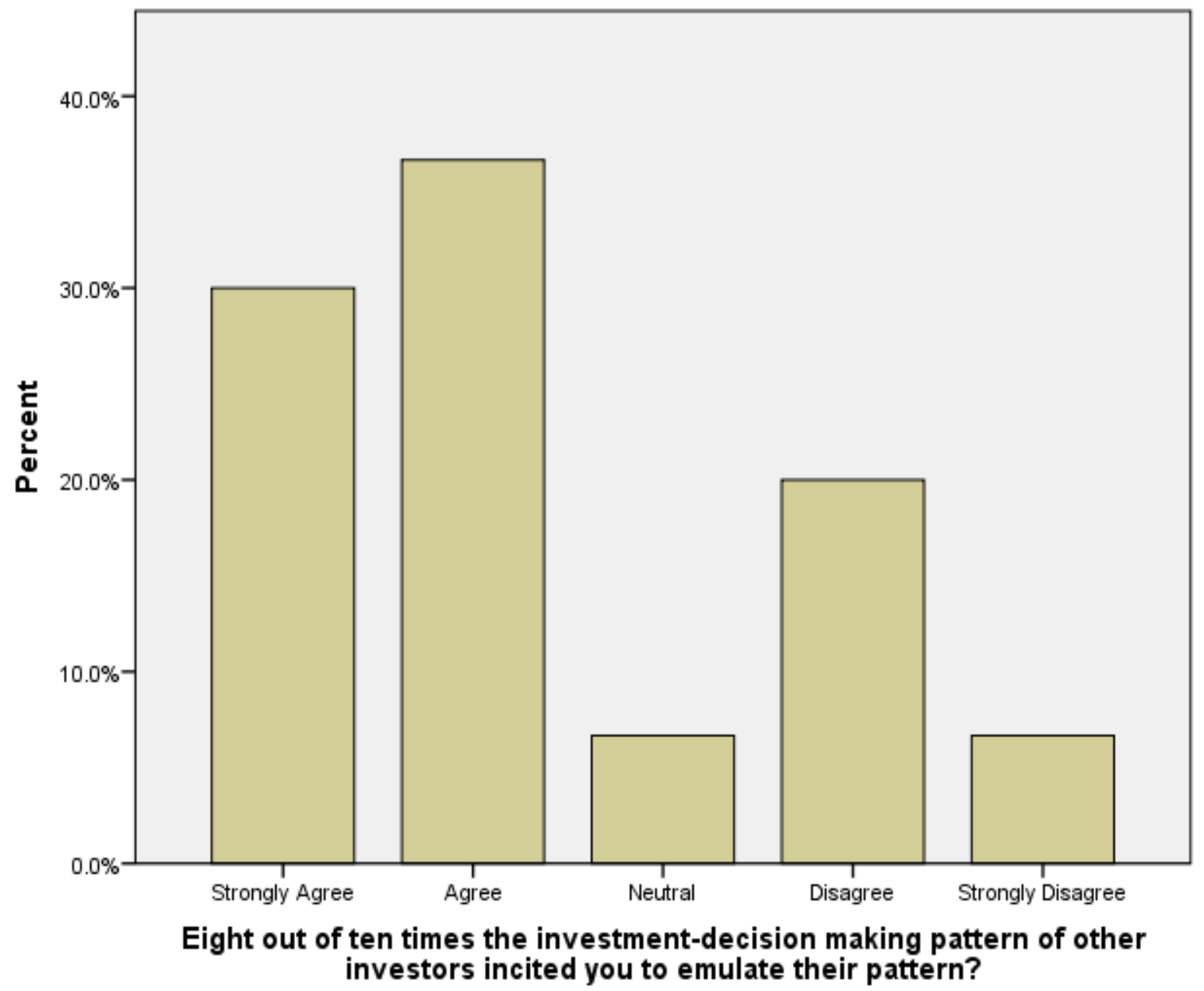

e. Eight out of ten times the investment-decision making pattern of other investors incited you to emulate their pattern?

This result has established that investors emulate the decision-making patterns of their counterparts. As the graph shows, more than $35 \%$ of the respondents gave agreed that they have followed the decision-making patterns of other investors in the market eight out of ten times. As per the definition of behavior finance, discussed in literature review, trying to emulate the decision-making pattern of other investors is also a part of behavior finance. Since more than 35 of the respondents have agreed and an almost $30 \%$ of them have strongly agreed to this statement, one can state that behavior finance is going to play a major role in future, with regard to the individual decision-making. 


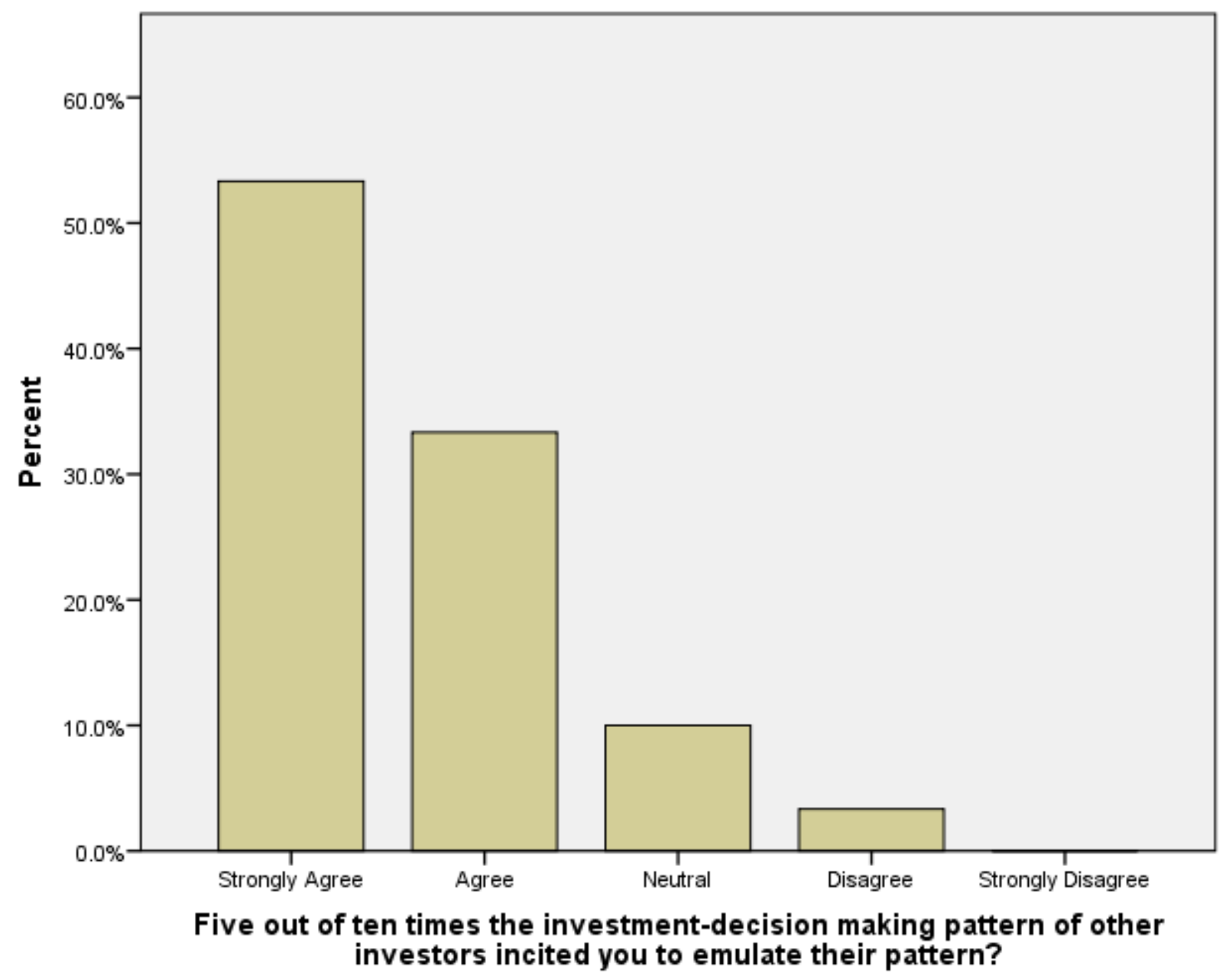

f. Five out of ten times the investment-decision making pattern of other investors incited you to emulate their pattern?

The results of this question has solidified the conclusion made from the results of the previous question. While in that question the majority of the respondents just agreed, in this question the majority of the respondents have strongly agreed. An almost 55\% of the individual investors have strongly agreed that they follow the investment decision-making pattern of other investors. 


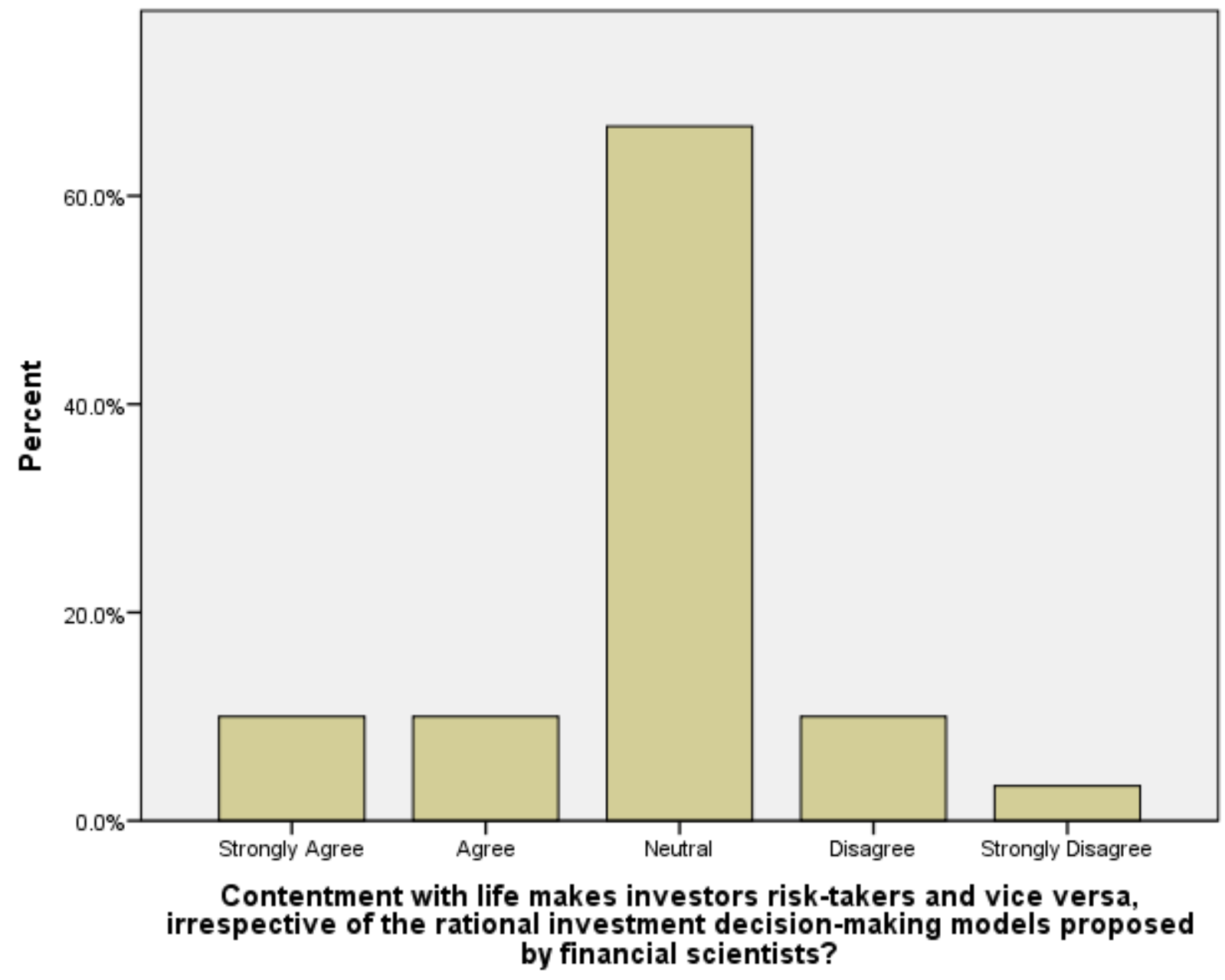

g. Contentment with life makes investors risk-takers and vice versa, irrespective of the rational investment decision-making models proposed by financial scientists?

Interestingly, these results tend to differ with the conclusion drawn from the above question. More than the $60 \%$ of the respondents have remained neutral to the question that contentment with life affected their risk perceptions. This indicates that contentment with life does not affect their investment decision-making behavior. This result has added to the on-going controversy on behavior finance, by implying that behavior is not absolutely linked to investment decision-making, and that the investors take into account market information and portfolio investment approaches while making financial decisions.

\section{Analysis of Institutional investors}




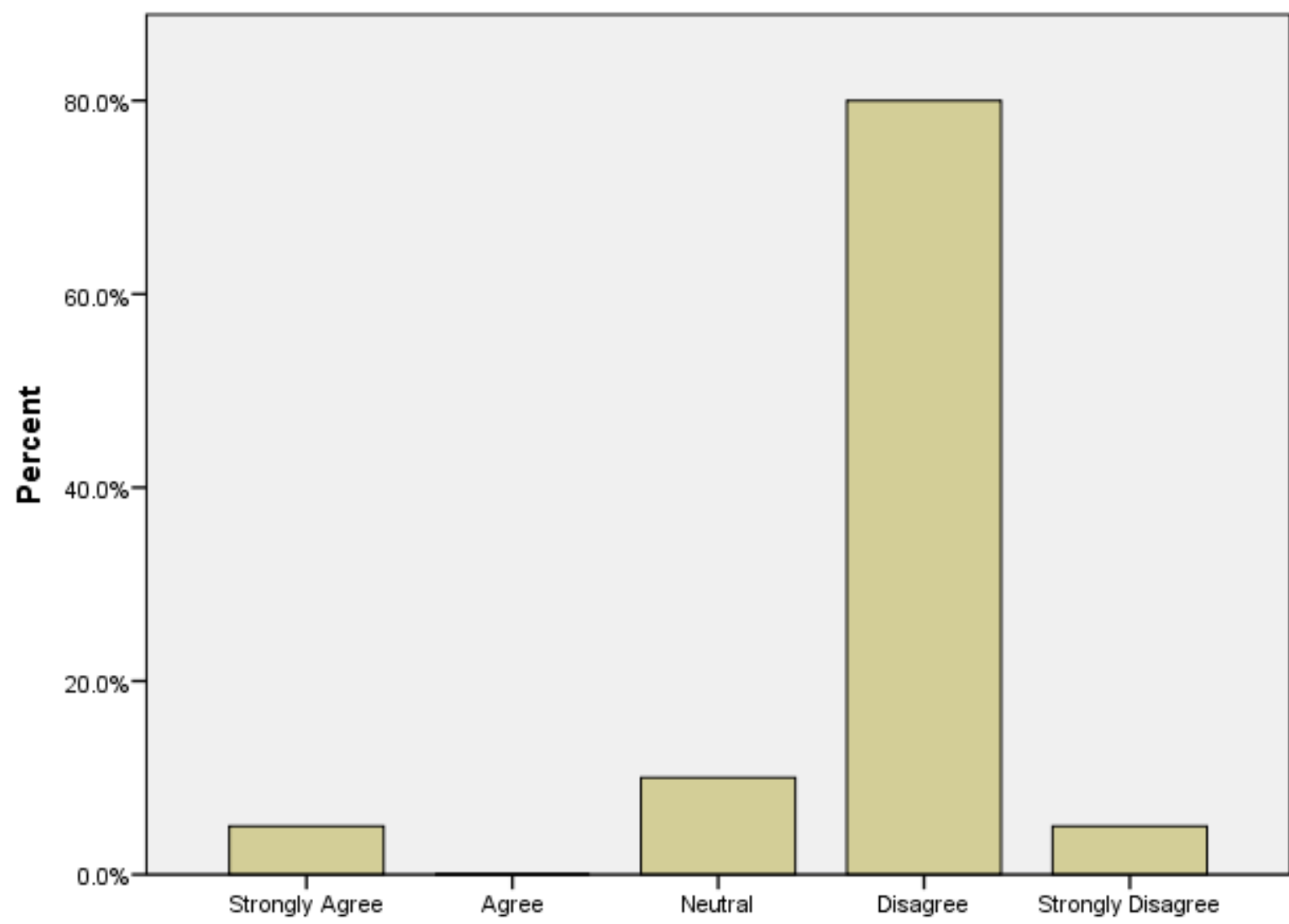

At the time of happiness, a greater number of stocks in the market were purchased than the same type of stocks purchased at the same price at the time of unhappiness?

a. At the time of happiness, a greater number of stocks in the market were purchased than the same type of stocks purchased at the same price at the time of unhappiness?

As the graph shows, an almost $80 \%$ of the respondents have rejected the contention that their mental state of happiness or unhappiness has anything to do with their investment decision-making. It must be kept in mind that this question was asked to the institutional investors, who were represented by their senior managers. This result shows the difference between the approach of the individual investors and that of the institutional investors. While most of the individual investors have accepted that their mental state affects their investment decisions, this has not been the case with the institutional investors. It can be concluded that institutional investors use portfolio approach like calculating expected rate of return and correlation coefficients between different types of securities for making investments.

This result implies that behavior finance has a dismal future, when it comes to institutional investors, while it has a great future when it comes to individual investors. However, researchers can add great value to the field of behavior finance, if they compare the rate of returns earned by the institutional investors with those of the individual investors. If the individual investors are earning better rate of returns that the institutional investors, then the behavior finance is going to dominate the upcoming decades of financial decision-making. 


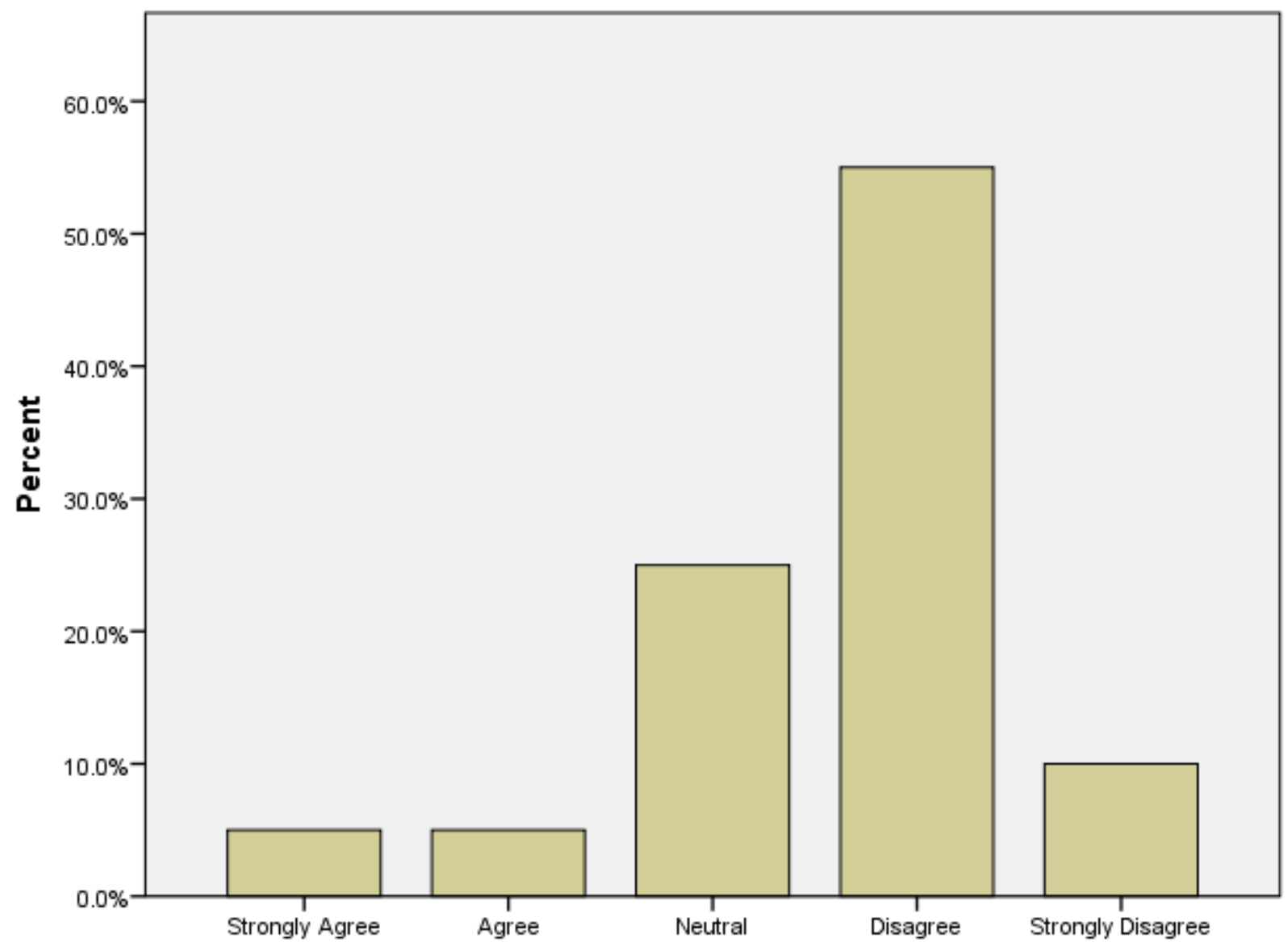

At the time of extreme excitement and enthusiasm, you were more willing to buy risky stocks than at the time of subdued and demoralized attitude?

b. At the time of extreme excitement and enthusiasm, you were more willing to buy risky stocks than at the time of subdued and demoralized attitude?

Just as in the case of above question, the institutional investors have rejected the notion that their excitement level has anything to do with their investment decisions. An almost 55\% of the respondents have rejected this contention. More than $20 \%$ have remained neutral, while $10 \%$ have strongly disagreed. As a matter of fact, institutions are different from individuals. They have scientific means and resources to apply rational approaches like Capital Pricing model. (Merton, R., 1973)Similarly, emotions have no significance for them, because institutions are not human beings; their existence is abstract. The indifference of the institutional investors has played down the role of behavior finance, if this result is considered. However, researchers can enhance the significance of behavior finance, if they manage to prove that the rate of returns earned from the rational decision making by the institutional investors is lower than the rate of return earned by the individual investors by applying their intuition. 


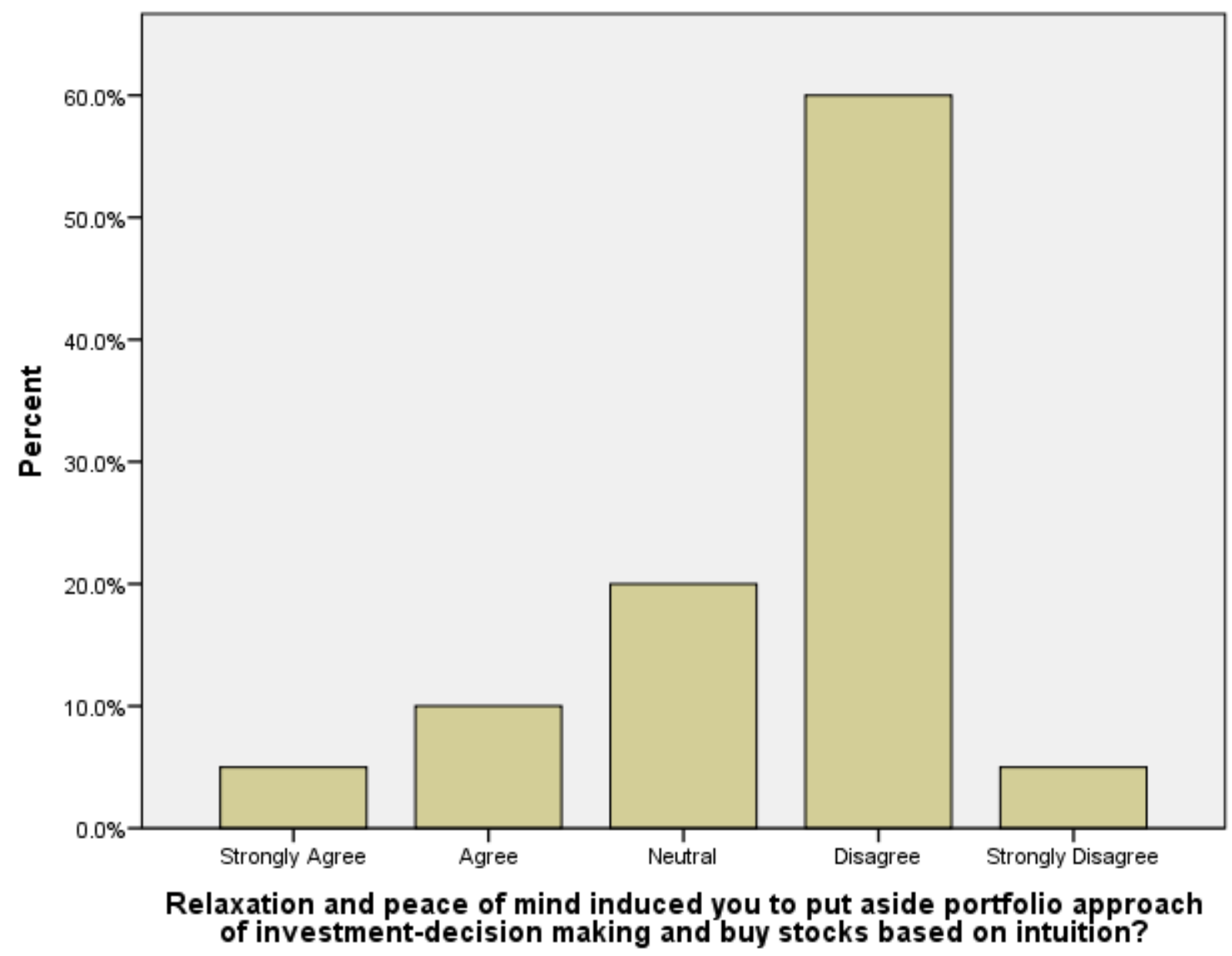

c. Relaxation and peace of mind induced you to put aside portfolio approach of investment-decision making and buy stocks based on intuition?

As the graph manifests, an almost $60 \%$ of the institutional investors represented by their senior managers have disagreed that relaxation and peace of mind prompts them to renounce portfolio approach of investment decision-making and to follow the dictates of their intuition. An almost $20 \%$ of the respondents have adopted neutrality regarding this statement. These results go on to confirm the conclusions made about the role of institutional investors in the above three questions, that is, their behavior is not linked to their investment decision-making. 


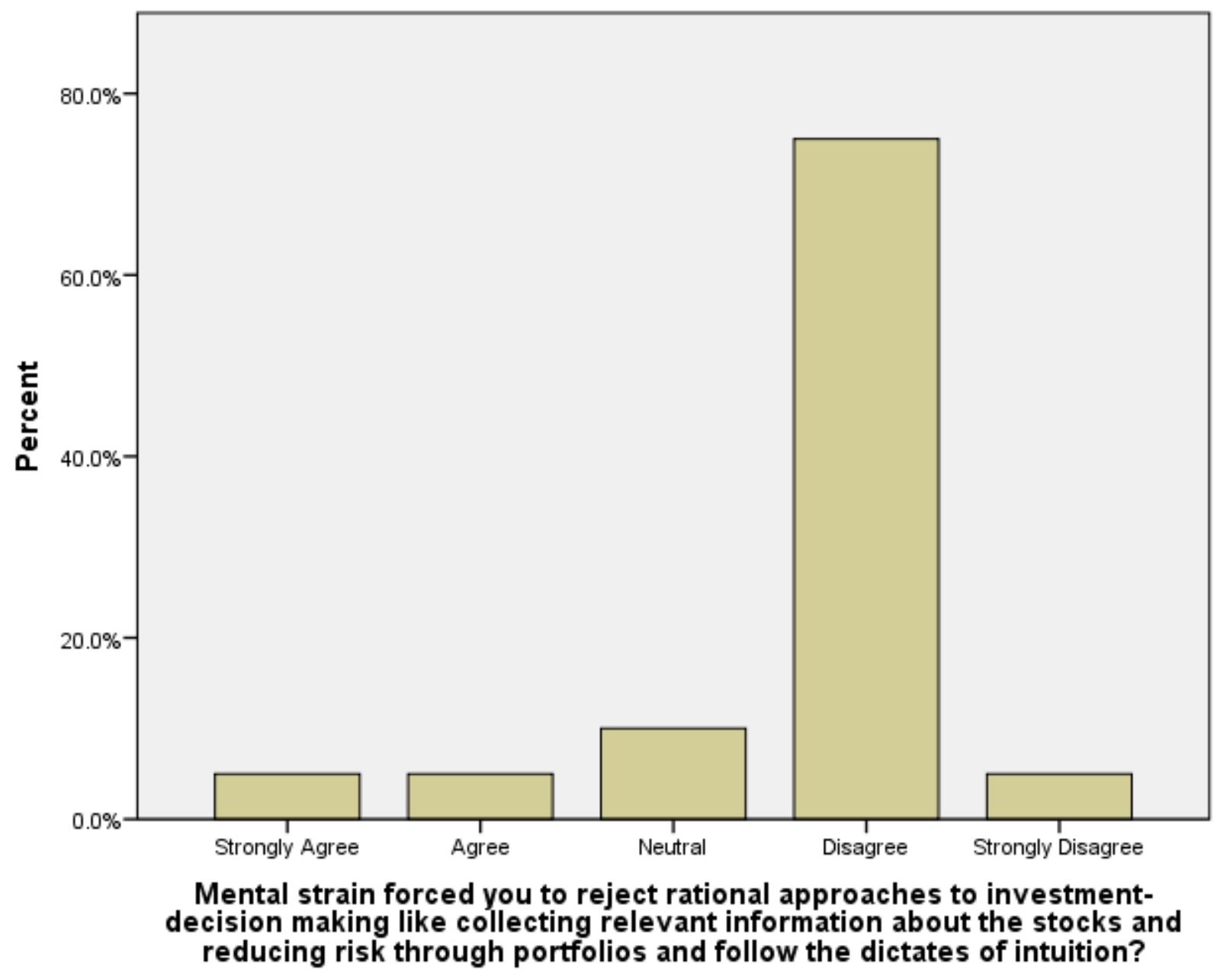

d. Mental strain forced you to reject rational approaches to investment-decision making like collecting relevant information about the stocks and reducing risk through portfolios and follow the dictates of intuition?

The graph shows that more than $70 \%$ of the respondents have disagreed with the contention that mental strain affects their investment decisions. This overwhelming percentage of the respondents indicates that behavior finance as a field is least practiced by the institutional investors. 


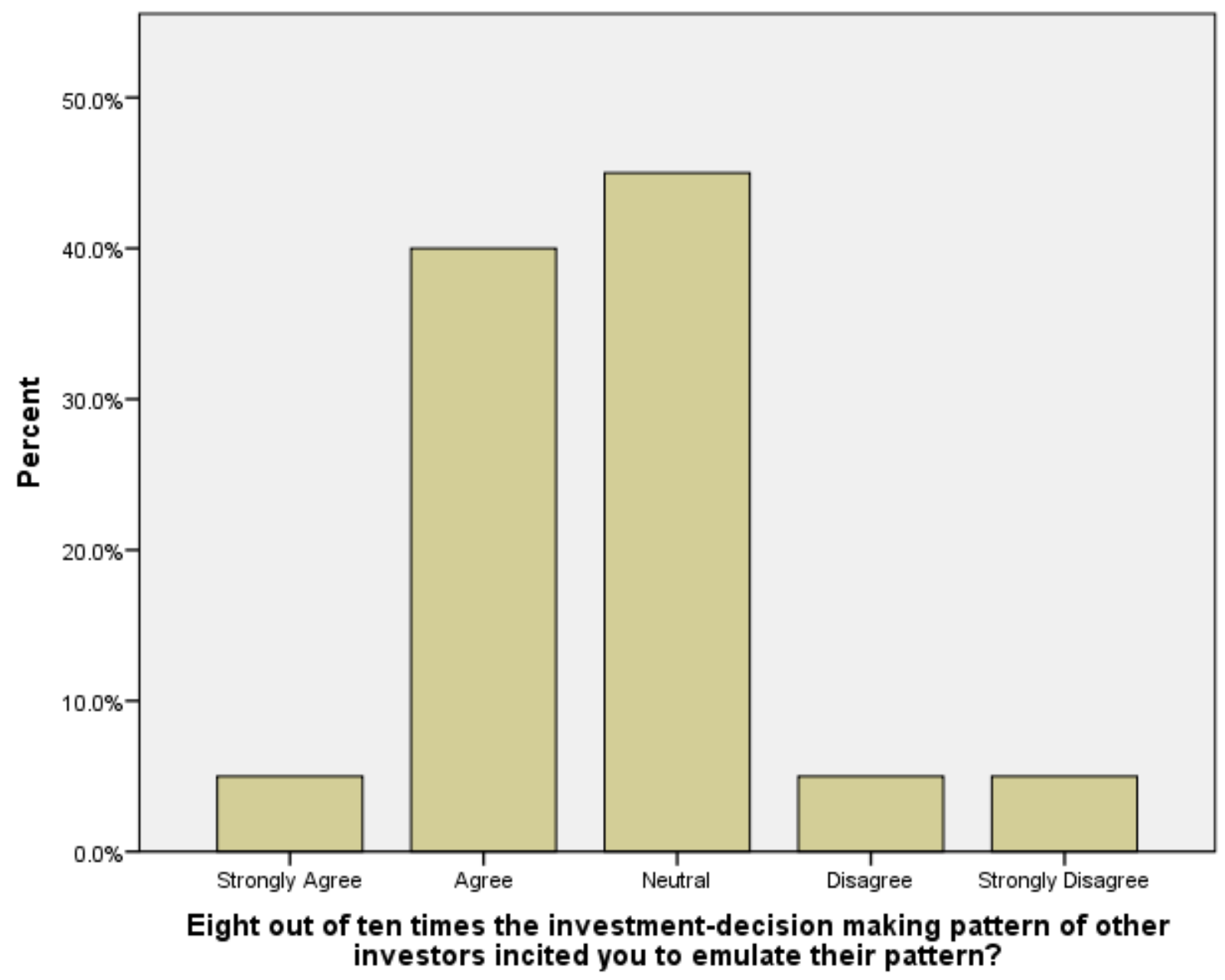

e. Eight out of ten times the investment-decision making pattern of other investors incited you to emulate their pattern?

The results state that almost $45 \%$ of the respondents have shown neutrality to the contention that they emulate the investment patterns of their counterparts in eight out of ten times. However, a less than $40 \%$ of the institutional investors have agreed that they follow the decision-making approaches of the other investors in eight out of ten times. Besides, 5\% have strongly agreed, and almost equal percentage of the respondents has disagreed. All in all, it can be concluded that just like the individual investors, institutional investors are also influenced by the investment decisions-making of their counterparts. However, compared to individual investors, they take into account other factors like considering capital pricing model, portfolio risk mitigation measures, and expected rate of return of the securities more frequently than the individual investors. 


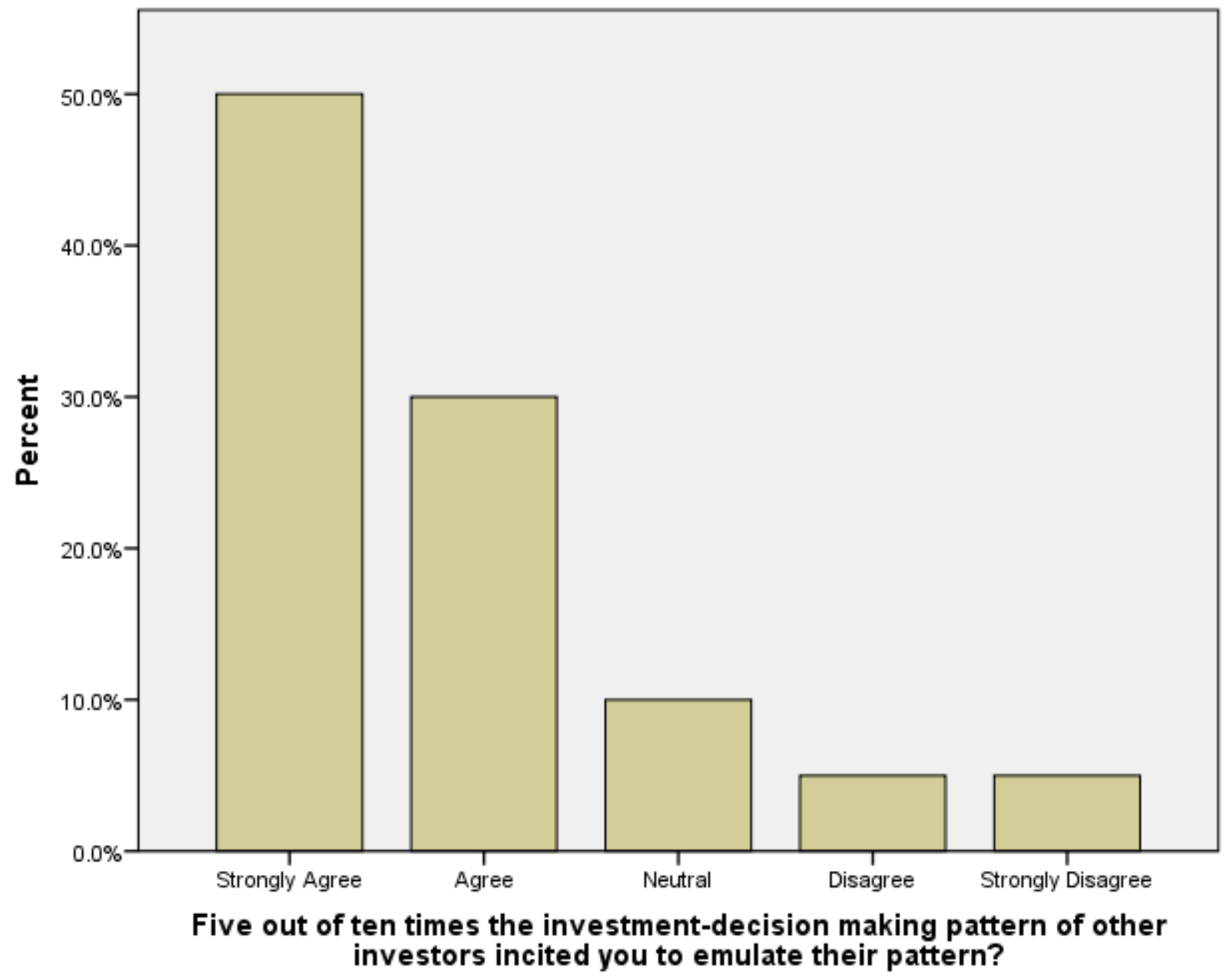

f. Five out of ten times the investment-decision making pattern of other investors incited you to emulate their pattern?

The graph shows that an overwhelming majority of almost $50 \%$ has strongly agreed that they are influenced by investment decision making of their counterparts, five out of ten times. This result is in line with the findings of the previous question. An almost $30 \%$ of the respondents have agreed to this statement, adding to the veracity of the conclusion that institutional investors are heavily influenced by their competitors. This is the only area of behavior finance where institutional investors have paid heed to it for investment decision-making, while they have largely ignored the other parameters of behavior finance as part of their decision-making process.

\section{Bottom-line of the analysis}

Four things have been discovered about contemporary behavior finance from the above analysis. First is that individual investors are more strongly driven by the vagaries of their behavior while making investment decisions than the institutions. Second is the fact that in some cases institutional investors also follow behavior finance, for example, while emulating investment patterns of their competitors, but largely they adopt rational approaches like Capital asset pricing model and portfolio theory of investment for making investments. The third discovery of this analysis is that behavior finance has a great future for individual investors, considering the fact that more and more individual investors are entering the market, as reported by the literature review. The fourth discovery is: "If the researchers manage to prove that rate of returns earned by the individual investors, whose investment decisions were affected by their behavior, is more than the rate of returns earned by the institutional investors, who applied rational approaches to decision-making, then that will add great value to the field of behavior finance".

\section{Discussion}

The purpose of this research was to review the field of behavioral finance and analyze its emergence in a new developed market. For this purpose, the Karachi Stock Exchange was selected for analysis of whether the basic propositions by behavioral finance are in alliance with the investment decision making of the market or not. The 
results show that investors in Karachi Stock exchange are in fact affected by the behavioral factors and that the point that the investors take into account for the purpose of investment decision making are in fact significant in explaining the return and risk factors of financial instruments. Simply this means that the perceptions of the investors do have a strong and significant impact on the financial decision making of the investors thus implying that behavioral finance in fact duly challenges the conventional financial modeling and thus is an important emerging field of financial decision making that definitely needs to be explored and studied further.

\section{Conclusion}

Finance, while largely emerging out of economics, has tended to overlook its own intellectual history. Perhaps because of this lack of attention to its intellectual history, an important connection between two important schools of thought, one in finance (behavioral finance) and the other in economics (institutional economics), appears to have been largely overlooked. The parallels between the two schools of thought are striking.

Behavioral finance is under construction as a solid structure of finance. It incorporates parts of standard finance, replaces others, and includes bridges between theory, evidence, and practice while adhering to the scientific rigor introduced by standard finance.

Behavioral finance substitutes normal people for the rational people in standard finance. It substitutes behavioral portfolio theory for mean-variance portfolio theory, and behavioral asset pricing models for the CAPM and other models where expected returns are determined only by risk. Behavioral finance also distinguishes rational markets from hard-to-beat markets in the discussion of efficient markets, a distinction that is often blurred in standard finance, and it examines why so many investors believe that it is easy to beat the market.

Behavioral finance expands the domain of finance beyond portfolios, asset pricing, and market efficiency. It explores the behavior of investors and managers in direct and indirect ways, whether by examining brains in fMRIs or examining wants, errors, preferences, and behavior in questionnaires, experiments, and the field. For example, behavioral finance explores saving and spending behavior, beyond portfolio formation, as savings underlie portfolios and are spent from them. And it explores financial choices affected by culture, fairness, social responsibility, and other expressive and emotional wants.

\section{References}

[1]. Edmans, A. (2011). Does the stock market fully value intangibles? Employee satisfaction and equity prices, Journal of Financial Economics, Vol. 101 (3) pp. $621-640$.

[2]. Hosseini, H. (2003). The arrival of behavioral economics: from Michigan, or the Carnegie School in the 1950s and the early 1960s?,The Journal of Socio Economics, Vol. 32, pp. 391 - 409.

[3]. Jegadeesh, N. (1995). Advances in Behavioral Finance by Richard H. Thaler, American Finance Association, Vol. 50 (1), pp. $396-400$

[4]. 2. Olivier et al. (2000). Principles of Finance Management, $1^{\text {st }}$ Ed. SA: Juta and Co.

[5]. 4. Rappaport, A. (2006). Ten Ways to Create Shareholder Value, HBR.

[6]. Shiller, R. (2003). From Efficient Markets Theory to Behavioral Finance, The Journal of Economic Perspectives, Vol. 17 (1) pp. 83 - 104

Saunders, M., 2009. Research Methods for Business Students. Financial Times Prentice Hall, ISBN: 9780273716860

[7]. Ghauri, P., 2005.Research Methods in Business Studies. Pearson Education Limited, England, ISBN: 13-978-0-273-68156-4

[8]. Jackson, S.L., 2009. Research Methods and Statistics: A Critical Thinking Approach. 3rd Ed. Belmont, CA: Wadsworth.

[9]. Cohen, L.\&Manion, L.\& Morrison, K., 2011. Research Methods in Education, 7th Ed. USA: Routledge

[10]. Holland, D., 2012. Integrating Knowledge Through Interdisciplinary Research, USA: Routledge 